\title{
TU/e EmonOWEN

\section{Moisture penetration in oak during sinusoidal humidity fluctuations studied by NMR}

\section{Citation for published version (APA):}

Arends, T., Pel, L., \& Smeulders, D. M. J. (2018). Moisture penetration in oak during sinusoidal humidity fluctuations studied by NMR. Construction and Building Materials, 166, 196-203.

https://doi.org/10.1016/j.conbuildmat.2018.01.133

DOI:

10.1016/j.conbuildmat.2018.01.133

Document status and date:

Published: 30/03/2018

\section{Document Version:}

Publisher's PDF, also known as Version of Record (includes final page, issue and volume numbers)

\section{Please check the document version of this publication:}

- A submitted manuscript is the version of the article upon submission and before peer-review. There can be important differences between the submitted version and the official published version of record. People interested in the research are advised to contact the author for the final version of the publication, or visit the $\mathrm{DOI}$ to the publisher's website.

- The final author version and the galley proof are versions of the publication after peer review.

- The final published version features the final layout of the paper including the volume, issue and page numbers.

Link to publication

\section{General rights}

Copyright and moral rights for the publications made accessible in the public portal are retained by the authors and/or other copyright owners and it is a condition of accessing publications that users recognise and abide by the legal requirements associated with these rights.

- Users may download and print one copy of any publication from the public portal for the purpose of private study or research.

- You may not further distribute the material or use it for any profit-making activity or commercial gain

- You may freely distribute the URL identifying the publication in the public portal.

If the publication is distributed under the terms of Article 25fa of the Dutch Copyright Act, indicated by the "Taverne" license above, please follow below link for the End User Agreement:

www.tue.nl/taverne

Take down policy

If you believe that this document breaches copyright please contact us at:

openaccess@tue.nl

providing details and we will investigate your claim. 


\title{
Moisture penetration in oak during sinusoidal humidity fluctuations studied by NMR
}

\author{
Thomas Arends ${ }^{a}$, Leo Pel ${ }^{\mathrm{a}, *}$, David Smeulders ${ }^{\mathrm{b}}$ \\ ${ }^{a}$ Department of Applied Physics, Eindhoven University of Technology, P.O. Box 513, 5600 MB Eindhoven, The Netherlands \\ ${ }^{\mathrm{b}}$ Department of Mechanical Engineering, Eindhoven University of Technology, P.O. Box 513, 5600 MB Eindhoven, The Netherlands
}

\section{H I G H L I G H T S}

- Experimental study on moisture penetration in oak using NMR.

- One-dimensional transport during sinusoidal humidity fluctuations.

- Different principal transport directions have different transport characteristics.

- Moisture transport described by diffusion equation with surface resistance.

- Influence of humidity range minor on transport behavior.

\section{A R T I C L E I N F O}

\section{Article history:}

Received 9 October 2017

Received in revised form 2 January 2018

Accepted 23 January 2018

Available online 22 February 2018

\section{Keywords}

Moisture transport

Wood

Sinusoidal humidity fluctuations

Nuclear magnetic resonance

Experimental study

\begin{abstract}
A B S T R A C T
Most natural fluctuations in relative humidity are cyclic of nature, e.g. daily or seasonal. During these fluctuations, hygroscopic materials exchange moisture with the surrounding air. The penetration of moisture into the material depends on the frequency of the fluctuation, but also on the transport characteristics of the material. Here we present an experimental study on the penetration depth of moisture in oak during sinusoidal relative humidity fluctuations, covering a wide range of frequencies. Using nuclear magnetic resonance, we show that the amplitude in moisture content decreases exponentially from the exposed surface. The slope of the decay on a logarithmic scale provides the diffusion coefficient in the three principal directions of wood (longitudinal, radial, tangential), which are in good agreement with literature values. Furthermore, we show the influence of the moisture content range on the decay in amplitude by performing experiments in different relative humidity ranges. Numerical experiments are performed to assess the dependence of moisture penetration on different model parameters.
\end{abstract}

(c) 2018 Elsevier Ltd. All rights reserved.

\section{Introduction}

A wide variety of wooden objects in the built environment is exposed to a fluctuating climate, e.g. furniture, construction elements in housing, but also works of art. A change in the ambient relative humidity results in moisture exchange between wood and air. As a consequence, the moisture content of the wood changes continuously. This can be advantageous since it contributes to the moisture buffering capacity of a room, ensuring a more stable indoor climate, affecting comfort but also energy consumption [1]. The buffering capacity of building materials has accordingly been subject of several studies [2-4], e.g. for application in building energy simulation [5-7]. Since the buffering

\footnotetext{
* Corresponding author.

E-mail address: l.pel@tue.nl (L. Pel).
}

capacity is governed by moisture transport, it is important to characterize transport behavior.

The penetration of moisture in wood has been studied extensively for step changes in the ambient relative humidity, including drying [8-12]. These conditions are, however, rare in the built environment; changes in relative humidity of indoor climates are most often cyclic. An example of a fluctuation in indoor relative humidity is shown in Fig. 1a for the grosse Galerie at Schönbrunn palace in Vienna, Austria. The cyclicality of the fluctuations is already apparent from the time-domain data, elucidated by the frequency spectrum after Fourier transform in Fig. 1b. Peaks at dominant fluctuations of one day and one year are immediately visible. Typical relative humidity fluctuations can thus be decomposed into a sum of sinusoidal fluctuations with different frequencies and amplitudes. The penetration of moisture into the material is dependent on the frequency of the external changes and the transport properties of the material [13,14]. Moisture will penetrate 

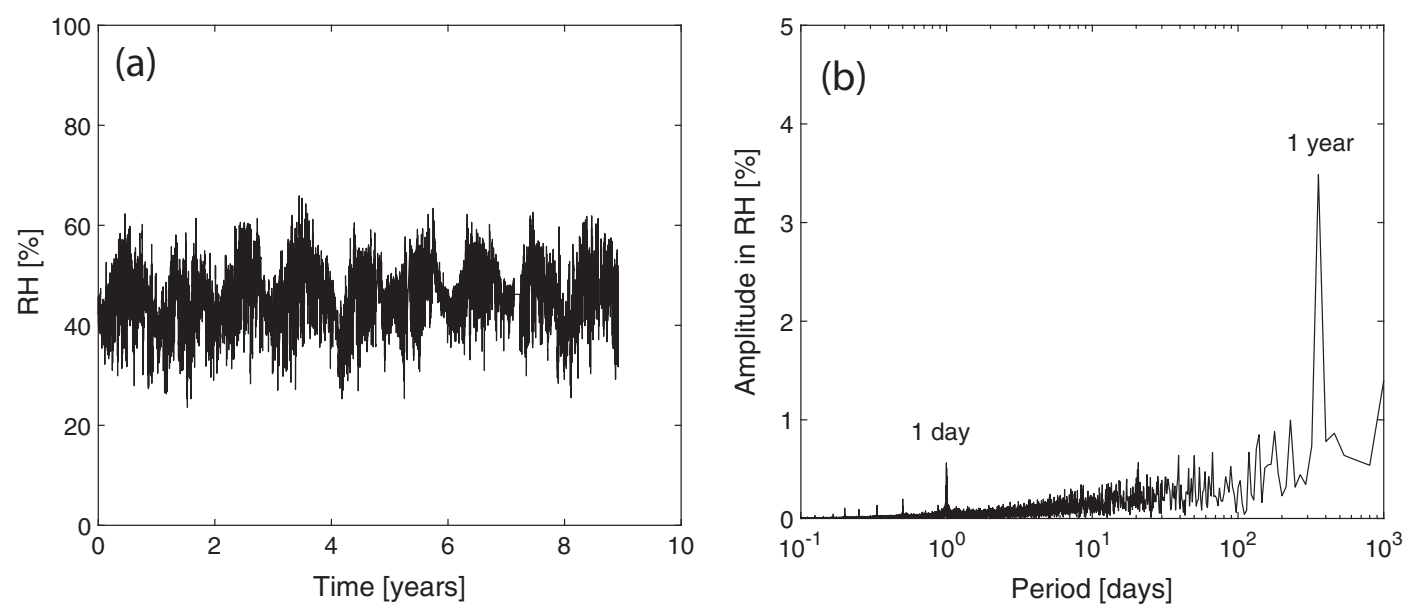

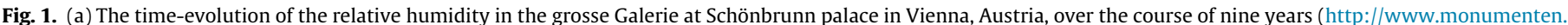
bwk.tue.nl/). (b) The frequency spectrum after Fourier transform, clearly showing peaks at dominant fluctuation frequencies.

further into the material when exposed to slow fluctuations. Furthermore, at the same fluctuation frequency, the penetration depth will be higher for a material which is more permeable to moisture.

The goal of this study is to investigate the penetration of moisture in oak during relative humidity fluctuations by nuclear magnetic resonance (NMR). This method has been applied before to study the moisture penetration in pine wood during daily alternating step changes in the relative humidity [15]. We intend to study a wider range of sinusoidal fluctuation frequencies to characterize the frequency dependence of moisture penetration in the different principal directions in oak. To this end, we first briefly introduce simple theory based on the diffusion equation. Experiments are then performed using NMR, in which the moisture content profile can be determined non-destructively during sinusoidal relative humidity fluctuations at various frequencies and different relative humidity ranges. The influence of the transport direction on the penetration depth is assessed by doing experiments in the different principal directions of the wood (longitudinal, radial, and tangential). Furthermore, the behavior in different moisture content regimes is explored. Results are discussed and compared to numerical calculations with a moisture-content dependent diffusion coefficient and an alternative moisture transport model. Finally, conclusions are drawn and an outlook is presented.

\section{Theory}

Many models have been proposed in the literature to describe moisture transport in wood, with a wide range of complexity. In this section, moisture transport in a wooden cylinder with a thickness $d$ will be treated. One surface is exposed to sinusoidal fluctuations in relative humidity, the back surface and side surface are sealed, resulting in one-dimensional moisture transport. Presuming a linear sorption isotherm and no surface resistance, this translates into a sinusoidal fluctuation in moisture content at the exposed surface. Regardless of the driving potential, transport in the material can be described by the diffusion equation [16]. Mathematically, transport can be described by

$\frac{\partial c}{\partial t}=\frac{\partial}{\partial x}\left(D \frac{\partial c}{\partial x}\right)$

where $c$ is the moisture content, $t$ time, $D$ the diffusion coefficient, and $x$ the distance from the exposed surface. Here, we will assume a constant diffusion coefficient $D$ to arrive at an analytical expres- sion for the moisture content. Initial and boundary conditions can be formulated as

$$
\begin{aligned}
& c(x, 0)=c_{i}, \\
& c(0, t)=c_{i}+A_{0} \sin (2 \pi f t), \\
& \frac{\partial c}{\partial x}(d, t)=0,
\end{aligned}
$$

where $c_{i}$ is the initial uniform moisture content, $A_{0}$ the amplitude in moisture content at the exposed surface, $f$ the frequency of the relative humidity changes, and $d$ the sample thickness. In the case of small penetration depths, i.e. in conditions for which the medium can be considered semi-infinite, the moisture content over time can be described analytically by [13]:

$c(x, t)=c_{i}+A_{0} e^{-k x} \sin (2 \pi f t-k x)$,

with $k$ the reciprocal of the penetration depth:

$k=\sqrt{\frac{\pi f}{D}}$.

Eq. (3) shows that the fluctuation in moisture content has a phase lag of $k x$, and the amplitude $A$ at a distance $x$ decays with $\mathrm{e}^{-\mathrm{kx}}$ away from the exposed surface:

$A(x)=A_{0} e^{-k x}$.

Rewriting terms in Eq. (5) and using Eq. (4) yields

$\ln \left(\frac{A}{A_{0}}\right)=-\sqrt{\frac{\pi}{D}} x \sqrt{f}$.

If moisture transport in the material can be described by the diffusion equation, the decay in amplitude should be linear on a logarithmic scale, when plotted versus the parameter $x \sqrt{ } f$. The slope of the amplitude decay then directly provides the diffusion coefficient.

In the experiments, a finite sample is used. The theory will therefore only hold in case the penetration of the moisture is considerably smaller than the thickness of the sample. Here we numerically assess the influence of sample finiteness on amplitude decay at different frequencies. To this end, we introduce dimensionless parameters, indicated by asterisk superscripts:

$c^{*}=\frac{c-c_{i}}{A_{0}}, t^{*}=\frac{D t}{d^{2}}, x^{*}=\frac{x}{d}, f^{*}=\frac{d^{2} f}{D}$. 
With these dimensionless parameters, we can transform Eqs. (1) and (2) to

$$
\left\{\begin{array}{l}
\frac{\partial c^{*}}{\partial t^{*}}=\frac{\partial^{2} c^{*}}{\partial x^{* 2}} \\
c^{*}\left(x^{*}, 0\right)=0 \\
c^{*}\left(0, t^{*}\right)=\sin \left(2 \pi f^{*} t^{*}\right), \\
\frac{\partial c^{*}}{\partial x^{*}}\left(1, t^{*}\right)=0
\end{array}\right.
$$

The equations in (8) are discretized, and simulations are performed with different frequencies $\left(f^{*}=0.5,1,2,5\right.$, and, 10). The decay in amplitude as a function of the dimensionless parameter $x^{*} \sqrt{ } f^{*}$ is shown in Fig. 2. For a semi-infinite sample, the decay is linear. For the finite sample, we see a deviation from the linear decay towards the back of the sample, where the amplitude is larger compared to a semi-infinite sample. Nevertheless, the amplitude decay of the first half of the sample is linear for frequencies $f^{*}$ larger than 1 . Even for $f^{*}=0.5$, the first half of the sample deviates only slightly from the decay of a semi-infinite sample. We can therefore expose finite samples to frequencies as low as $f^{*}=0.5$, if we only consider the half of the sample closest to the surface. Using literature values for $D$ of oak $[17,18]$ and the sample thickness, we can determine the range of frequencies of interest for our experiments using the definition of $f^{*}$ in Eq. (7). The diffusion coefficients are dependent on the direction in which transport occurs. Assuming diffusion coefficients of $1 \cdot 10^{-9} \mathrm{~m}^{2} / \mathrm{s}, 5 \cdot 10^{-11}$ $\mathrm{m}^{2} / \mathrm{s}$, and $2.5 \cdot 10^{-11} \mathrm{~m}^{2} / \mathrm{s}$ for transport in longitudinal, radial, and tangential direction respectively, we yield maximum fluctuation periods of 27,1111 , and $2222 \mathrm{~h}$.

\section{Materials and methods}

The material used in the measurements is white oak heartwood. Its structure contains large earlywood vessels, with typical diameters of $100-300 \mu \mathrm{m}$ (measured with a Dino-Lite ${ }^{\odot}$ digital microscope); latewood vessel diameters are typically 30-50 $\mu \mathrm{m}$. Other significant microstructural elements in oak include rays and long, thick-walled fiber tracheids or cells, whose diameter is much smaller than the typical vessel diameter. Moisture transfer between bordering cells occurs through pits or perforation plates, with approximate pit diameters of $6 \mu \mathrm{m}$ [19]. These pits have openings typically smaller than $100 \mathrm{~nm}$, with a reported mean of $30 \mathrm{~nm}$ [19]. These pits, and in particular their thickness, influence moisture transport characteristics of wood species to a large extent. For a more elaborate and detailed discussion of the microstructure of hardwoods, the reader is referred to specialized literature $[19,20]$.

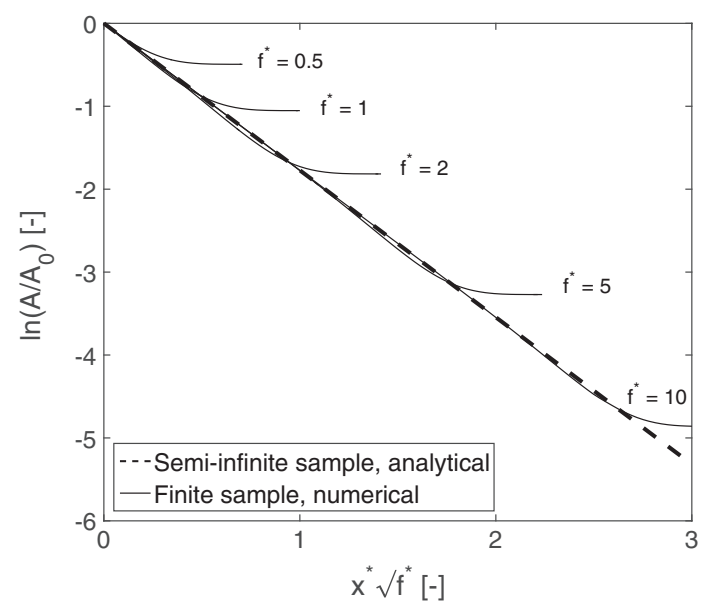

Fig. 2. Amplitude decay as a function of the dimensionless parameter $x^{*} \sqrt{ } f^{*}$ for different dimensionless frequencies $f^{*}$.
Cylindrical oak samples are prepared with their axis along either one of the principal macroscopic directions of wood. These principal directions are the longitudinal direction, i.e. along the growth direction of the tree; the radial direction, i.e. from the center of the tree to the outer bark; and the tangential direction, i.e. perpendicular to both longitudinal and radial direction and tangential to the annual rings of the tree. The cylinders have a diameter of $20 \mathrm{~mm}$ and a height of $10 \mathrm{~mm}$. Accordingly, several consecutive layers of earlywood and latewood are present in a single sample. The side surface and bottom of the cylinders are sealed by a thick layer of Krytox ${ }^{\odot}$ Teflon grease, ensuring onedimensional transport from the exposed surface. The sealed sample is placed inside a Teflon sample holder, where air can be blown over the top surface using a humidifier [18]. The humidifier mixes a dry and a wet air stream; their mixing proportions determine the relative humidity of the resulting air stream. Moisture content profiles along the height of the sample are measured using NMR. The key concept of NMR is that nuclei (e.g., ${ }^{1} \mathrm{H},{ }^{13} \mathrm{C}$ ) possess spin, and consequently have a magnetic dipole moment. In an externally applied magnetic field $B_{0}$, these nuclei precess at a resonance frequency

$f_{L}=\gamma B_{0}$,

where $\gamma$ is the gyromagnetic ratio of the nucleus (for ${ }^{1} \mathrm{H}, \gamma / 2 \pi=$ $42.58 \mathrm{MHz} / \mathrm{T}$ ). This resonance condition allows the selective measurement of nuclei in an NMR experiment by applying suitably chosen radiofrequency ( $R F)$ pulses. Moreover, when a gradient in the static field is applied, the resonance condition can be made spatially selective. Accordingly, the moisture content of a thin slice can be determined by changing the resonance frequency $f_{L}$.

The experiments described in this study are performed on a custom-built NMR system, specifically designed for quantitative measurement of moisture in porous materials. The system operates with a static magnetic field of $0.78 \mathrm{~T}$, using a magnetic field gradient of $\sim 0.3 \mathrm{~T} / \mathrm{m}$ in the vertical direction generated with Anderson coils [21]. The set-up is shown schematically in Fig. 3. The Teflon sample holder containing the sample of interest is placed inside a coil to transmit and receive RF fields during the NMR experiments. A Faraday shield is placed between the coil and the sample to suppress the effects of a varying dielectric permittivity induced by moisture content changes, thereby enabling quantitative measurement. Moisture content profiles are measured by performing Hahn spin-echoes [22] at different frequencies, i.e. at different heights, without moving the sample. To account for

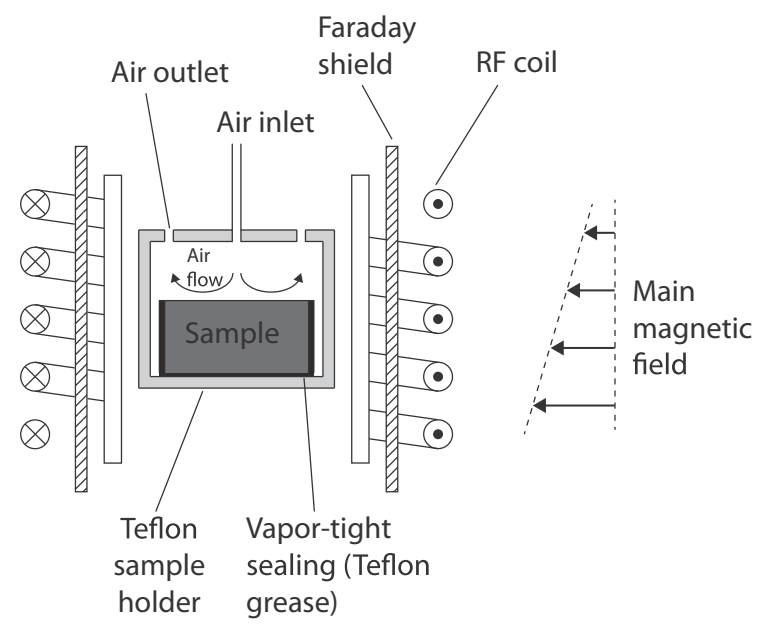

Fig. 3. Cross-section of the NMR set-up as used in the experiments to assess 1D moisture transport 
the decreasing sensitivity of the coil away from its center frequency, obtained values are divided by a reference profile obtained with a solution containing $0.1 \mathrm{M} \mathrm{CuSO}_{4}$. Accordingly, we can measure moisture inside the porous structure of wood, e.g. as water inside the cell walls or as liquid water in fiber cells or vessels. Latter is not the case in our experiments, since the moisture content is below the fiber saturation point marked by the absence of liquid water. Hence, we measure the concentration of bound water inside the cell walls. The cell spaces themselves are filled with water vapor, which, due to its low concentration, is not measured by NMR.

\section{Results and discussion}

\subsection{Influence of transport direction}

An example of the moisture content profile of the sample during a sinusoidal fluctuation in relative humidity is shown in Fig. 4a, for a sample with its axis in the longitudinal direction. As can be seen, the change in moisture content is the largest near the exposed surface, and damps towards the sealed back surface. This is also observed in the moisture content evolution over time at the different distances from the exposed surface in Fig. 4b. The moisture content evolution at the different measurement points can be fitted with a sine function to acquire the amplitude in moisture content as a function of frequency and distance from the exposed surface. These results can then be used to determine the penetration depth of moisture in the different directions of oak.

Fig. 4a and b show that the moisture content at the sealed back surface of the sample fluctuates too; strictly speaking, the sample length cannot be assumed infinite. We did, however, show that for the considered fluctuations, the moisture content near the exposed surface is not affected by the finiteness of the sample. By taking into account only the first half of the sample, this effect is omitted.

The resolution in the experiments is $2 \mathrm{~mm}$; each point we measure is an average over a slice of $2 \mathrm{~mm}$. The signal at each point within $1 \mathrm{~mm}$ of the surface will thus also be an average containing the signal outside the sample. We therefore omit these data points to include only information on the moisture content $1 \mathrm{~mm}$ away from the exposed surface. We can fit the distance-dependent logarithm of the amplitude linearly to retrieve the amplitude in normalized moisture content at the exposed surface. The decay of the amplitude as a function of $x \sqrt{ } f$ is shown in Fig. 5a for the three principal directions of wood (longitudinal, radial, and tangential). The decay in all three directions is linear, as expected from transport according to the diffusion equation with constant coefficients. Furthermore, the three directions are clearly distinguishable, with the decay being the steepest in the tangential and radial direction, and more slowly decaying in the longitudinal direction.

A linear fit with Eq. (6) provides diffusion coefficients for the different directions. For the longitudinal direction, a value of $2.9 \cdot 10^{-9} \mathrm{~m}^{2} / \mathrm{s}$ is found. The diffusion coefficient in the radial direction $\left(D=5.5 \cdot 10^{-11} \mathrm{~m}^{2} / \mathrm{s}\right)$ corresponds well to values found from an alternative method, in which the macroscopic bending of an oak board is used to retrieve the diffusion coefficient [18]. Furthermore, it is in good agreement with other values from literature [17]. The diffusion coefficient in the tangential direction has a value of $2.3 \cdot 10^{-11} \mathrm{~m}^{2} / \mathrm{s}$, which is consistent with qualitative information that the diffusion coefficient is the lowest in the tangential direction [19]. The presence of large vessels explains the high value for the diffusion coefficient in the longitudinal direction; although both water vapor and bound water diffusion occur, water vapor diffusion dominates the overall transport since it is much faster. Adsorption of the water from the vapor phase into the cell wall then results in an increase in measurable moisture content. The timescale of the latter process is presumed to be shorter than the transport timescale, otherwise an additional attenuation would be expected based on fluctuation frequency. For transport in radial or tangential direction, moisture is transported over cell walls and through pits, which largely increases the transport timescale. This can be schematized as diffusion in series, with consecutive vapor transport through cell spaces and bound water diffusion through cell walls [12]. Since bound water diffusion is slower, it is the limiting factor in the overall transport. The faster transport in radial direction can possibly be attributed to more pits on the radial surfaces of the cells or to the presence of rays in the radial direction.

The amplitude decay as a function of $k x$, i.e. as a function of the distance from the surface scaled by the penetration depth, is shown in Fig. 5b for the three different principal transport directions. Use is made of the derived diffusion coefficients derived in Fig. $5 \mathrm{a}$, in order to scale all three principal directions onto one curve. The figure illustrates the similarity in decay in the three different directions. The theoretical slope $(-1)$ from Eq. (6) is added to demonstrate the agreement with the penetration depth from the diffusion equation.

Using the derived diffusion coefficients of the different principal transport directions, the penetration depth as a function of
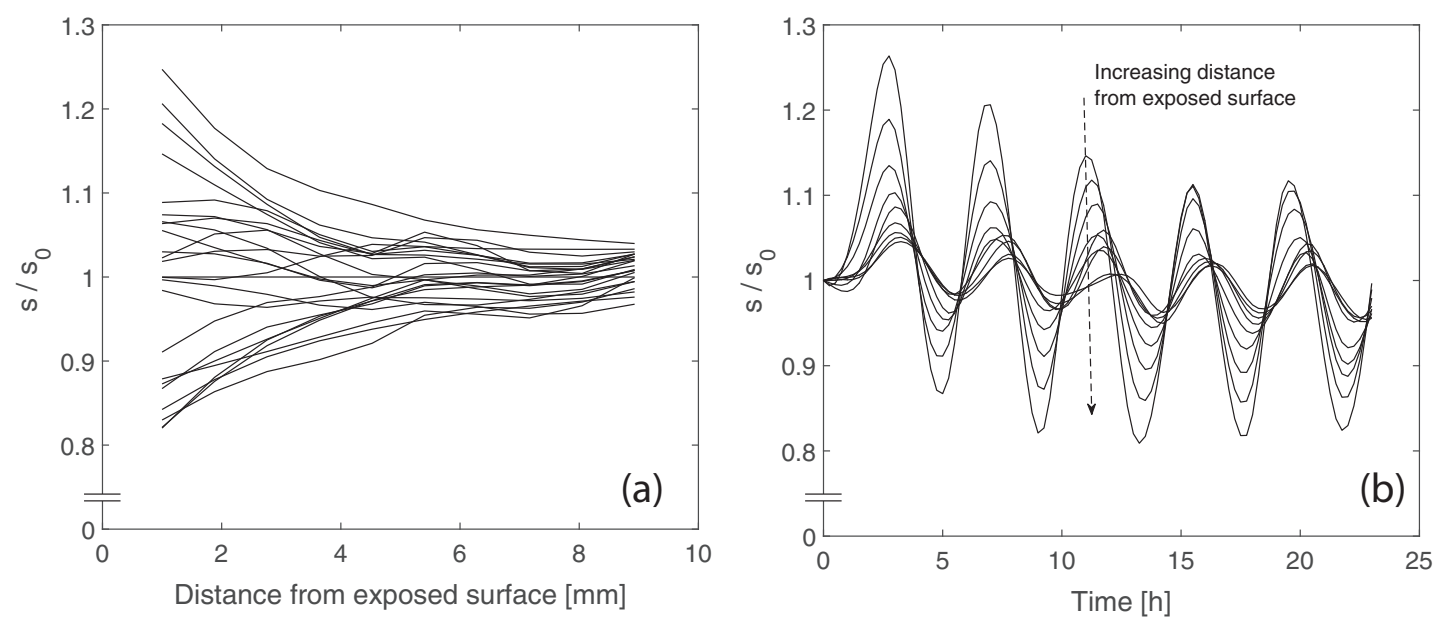

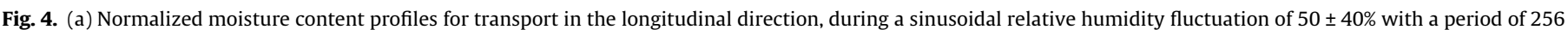

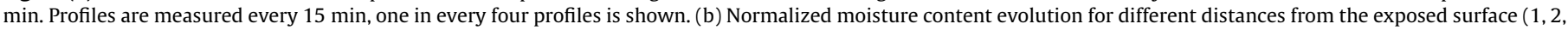
$3,4,5,6,7,8,9 \mathrm{~mm}$ ) during the same experiment. 

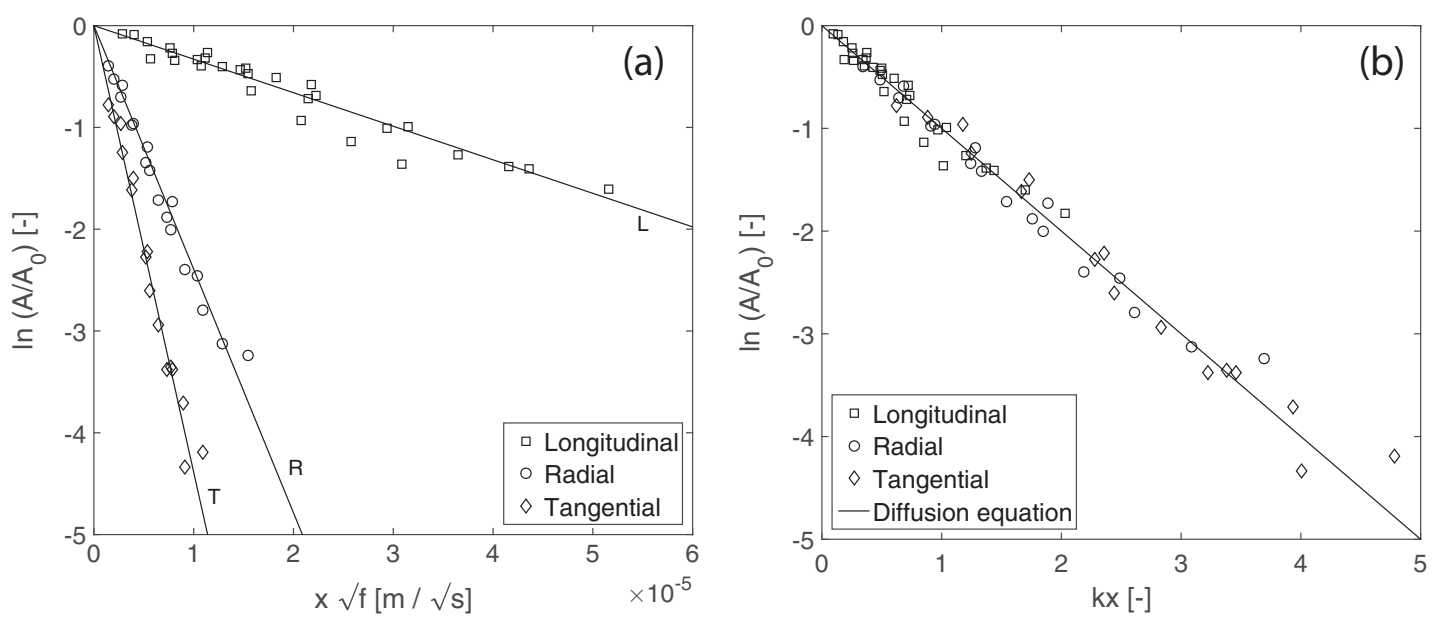

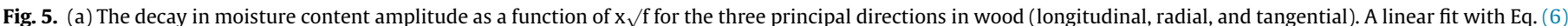

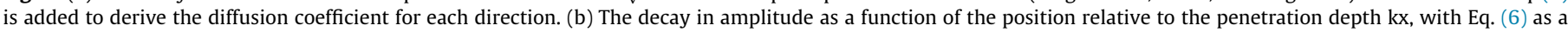
solid line.

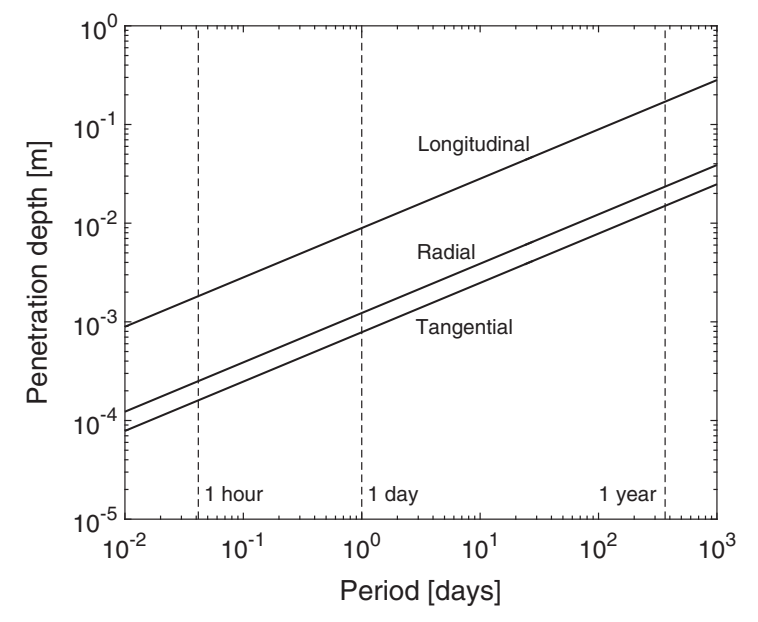

Fig. 6. The penetration depth of moisture as a function of the period of a sinusoidal fluctuation for the three different principal transport directions. Vertical dotted lines indicate main fluctuation periods of one hour, one day, and one year.

fluctuation frequency is shown in Fig. 6 for the three different principal directions. The figure insightfully shows that, for a given fluctuation frequency, the penetration depth is the highest in the longitudinal direction, and the lowest in the tangential direction. For an hourly fluctuation, the moisture penetrates $\sim 1.8 \mathrm{~mm}$ into the longitudinal direction, $\sim 0.25 \mathrm{~mm}$ in the radial direction, and $\sim 0.16 \mathrm{~mm}$ in the tangential direction. During daily fluctuations, the penetration depth is $9 \mathrm{~mm}, 1.2 \mathrm{~mm}$, and $0.8 \mathrm{~mm}$ for the longitudinal, radial, and tangential direction respectively; for the yearly fluctuation, these values are $17 \mathrm{~cm}, 2.3 \mathrm{~cm}$, and $1.5 \mathrm{~cm}$ respectively.

\subsection{Non-constant diffusion coefficient}

The experiments so far have covered almost the total hygroscopic moisture content range by fluctuating the relative humidity between 10 and 90\%. In literature, however, moisture contentdependent values have been proposed for the diffusion coefficient of moisture in wood [8,23-25]. The influence of a moisture content-dependent diffusion coefficient on the amplitude decay is assessed numerically first. Again we consider one-dimensional transport, with the exposed surface subjected to sinusoidal fluctu- ations in relative humidity, similar to Eq. (1). We can, similar to Eq. (7) introduce the following dimensionless parameters:

$c^{*}=\frac{c-c_{i}}{A_{0}}, t^{*}=\frac{D_{a} t}{d^{2}}, x^{*}=\frac{x}{d}, D^{*}=\frac{D}{D_{a}}, f^{*}=\frac{d^{2} f}{D_{a}}$,

where $D_{a}$ is the average diffusion coefficient over the moisture content range considered. With these dimensionless parameters, the equations in (1) and (2) can be scaled to arrive at

$\frac{\partial c^{*}}{\partial t^{*}}=\frac{\partial}{\partial x^{*}}\left(D^{*} \frac{\partial c^{*}}{\partial x^{*}}\right)$

The initial and boundary conditions are the same as in (8). The scaled diffusion coefficient $D^{*}$ is assumed to be of exponential form, i.e.

$D^{*}=\frac{\beta}{e^{\beta}-e^{-\beta}} e^{\beta c^{*}}$,

where $\beta$ determines the influence of the diffusion coefficient on scaled moisture content. For increasing $\beta$, the diffusion coefficient has a stronger dependence on moisture content. The form of the diffusion coefficient is chosen such that the average scaled diffusion coefficient over the scaled moisture content range (from -1 to +1 ) is unity. For small values of $\beta$, simulations can be scaled with $x^{*} \sqrt{ } f^{*}$, as is shown in Fig. 7a for $\beta=1$. The amplitude decay is, similarly to $\beta=0$, exponential.

If the diffusion coefficient is dependent on moisture content, the amplitude decay is additionally affected by the moisture content range in which the fluctuation occurs. This effect is shown in Fig. 7a for $\beta=1$, exposed to different scaled moisture content fluctuations at the surface $(0 \pm 1,-0.5 \pm 0.5,0 \pm 0.5$, and $0.5 \pm 0.5$ ). Even for this relatively weak dependence of the diffusion coefficient on moisture content, the decay in the three different moisture content ranges is clearly distinguishable. The slope of the decay becomes less negative for increasing moisture content range, since the diffusion coefficient increases with moisture content. It is therefore expected that, when performing experiments in different moisture content ranges, the decay in amplitude is different if the diffusion constant is dependent on the moisture content. Experiments are accordingly performed with the longitudinal sample, which is exposed to relative humidity fluctuations of $30 \pm 20 \%, 50 \pm 20 \%$, and $70 \pm 20 \%$, with different frequencies (periods of $4.25,8.5$, and $17 \mathrm{~h}$ ). The resulting decay in moisture content amplitude as a function of $x^{*} \sqrt{ } f^{*}$ (using the diffusion coefficient 

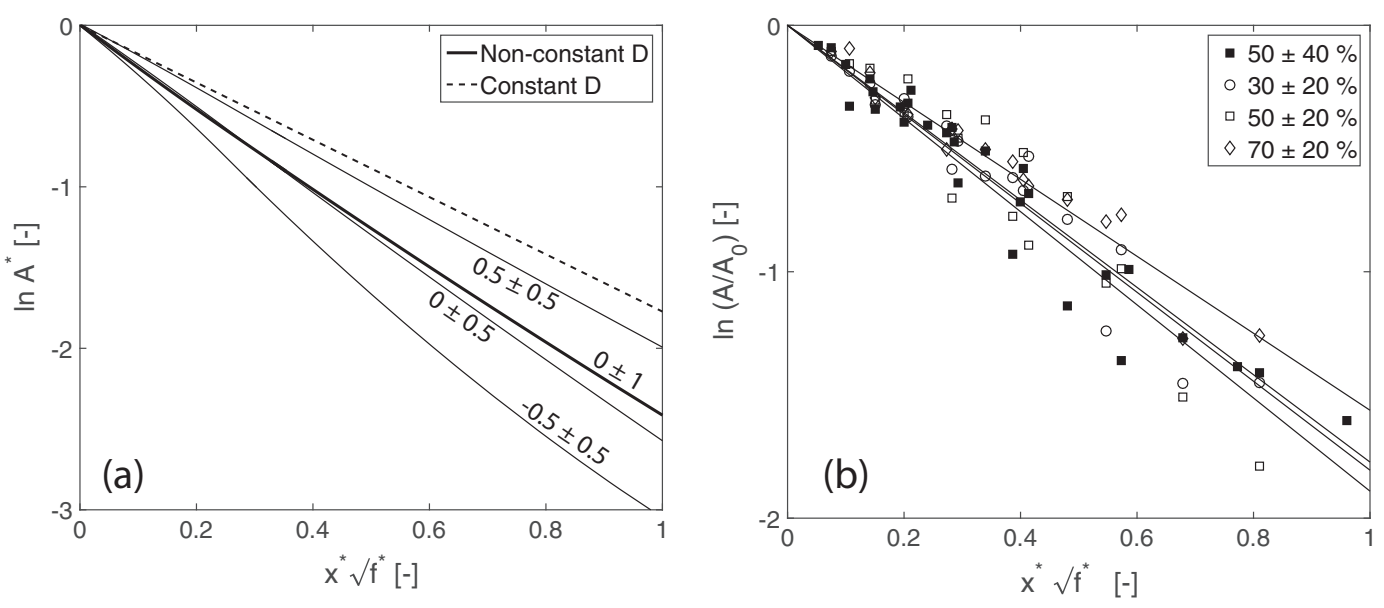

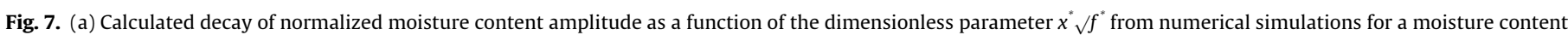

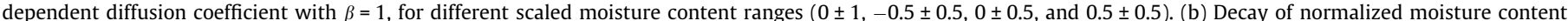

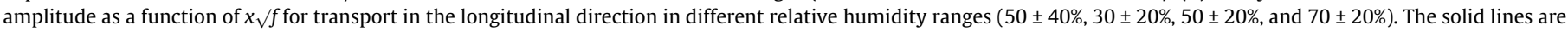
linear fits with the experimental data.

derived in Fig. 5a is shown in Fig. 7b. The linear fits with the experimental data for the four different relative humidity regimes are similar $\left(2.9 \cdot 10^{-11} \mathrm{~m}^{2} / \mathrm{s}, 2.8 \cdot 10^{-11} \mathrm{~m}^{2} / \mathrm{s}, 2.5 \cdot 10^{-11} \mathrm{~m}^{2} / \mathrm{s}\right.$, and $3.7 \cdot 10^{-11} \mathrm{~m}^{2} / \mathrm{s}$ for $50 \pm 40 \%, 30 \pm 20 \%, 50 \pm 20 \%$, and $70 \pm 20 \%$ respectively). We can therefore conclude that, in the longitudinal direction of oak, the kinetics of moisture transport is almost independent of the moisture content regime and can thus be well described by a constant diffusion coefficient.

\subsection{Influence of surface resistance}

In the above analysis, we have assumed immediate equilibrium between moisture at the exposed surface and in the ambient air. If this is the case, the amplitude in moisture content at the exposed surface should be independent of fluctuation frequency. We therefore first determine the amplitude in moisture content at infinitely slow fluctuations $A_{\infty}$ as half of the difference between the equilibrium moisture content at relative humidities of $10 \%$ and $90 \%$. Due to the resolution, the first point we measure is at $x_{1}=1 \mathrm{~mm}$ from the surface. According to Eq. (6), the amplitude at this point divided by $A_{\infty}$ should decay exponentially with the square root of frequency. When additionally scaled by the diffusion coefficient,

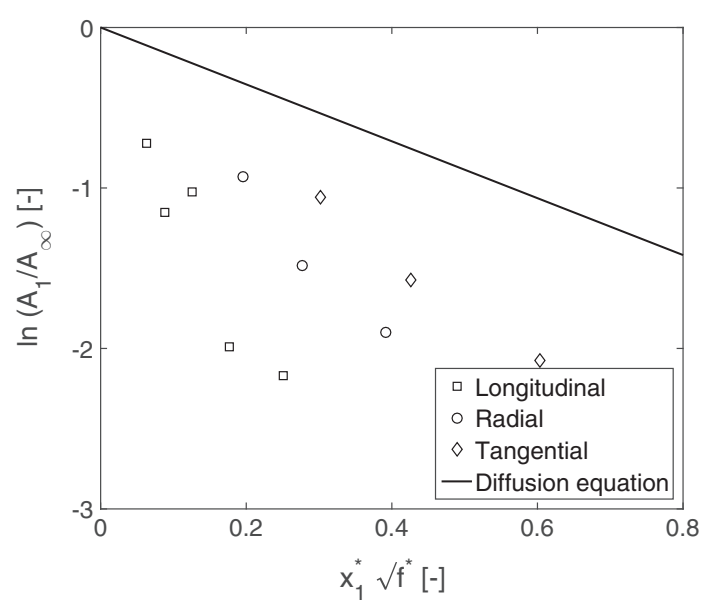

Fig. 8. The amplitude in moisture content at $1 \mathrm{~mm}$ from the exposed surface $\left(x_{1}^{*}=\right.$ 0.1 ) divided by the amplitude for infinitely slow fluctuations (i.e. the difference in equilibrium moisture content at a relative humidity of $10 \%$ and $90 \%$ ). the amplitude at $x_{1}$ should be independent of transport direction. This is contradicted by experimental results in Fig. 8, where the decay is steeper than predicted from the diffusion equation in Eq. (6). Furthermore, the results for the three different transport directions are not scaled onto one master curve.

The amplitude at the exposed surface is thus attenuated. A possible cause is the resistance resulting from a boundary layer, damping the amplitude in moisture content at the exposed surface. The influence of this surface resistance at the wood-air boundary on the penetration depth of moisture can be incorporated by replacing the boundary condition at $x^{*}=0$ in (11) with

$\frac{\partial c^{*}}{\partial x^{*}}\left(0, t^{*}\right)=g^{*}\left[c^{*}\left(0, t^{*}\right)-\sin \left(2 \pi f^{*} t^{*}\right)\right]$,

with $g^{*}=g d / D \rho$, $g$ being a mass transfer coefficient $\left[\mathrm{kg} / \mathrm{m}^{2} \mathrm{~s}\right]$ and $\rho$ the density of wood $\left[\mathrm{kg} / \mathrm{m}^{3}\right]$. The normalized moisture content amplitude as a function of $x^{*} \sqrt{ } f^{*}$ is shown in Fig. 9a, resulting from simulations with various values of $g^{*}(0.01,0.1,1)$. The decays for the three different values of the dimensionless mass transfer coefficient $g^{*}$ are indistinguishable; similar to Eq. (6), all three are linear with slope $-\sqrt{ } \pi$. This independence of the penetration depth on the surface resistance was already recognized by Cunningham [14]. The amplitude at the exposed surface, however, decreases with dimensionless frequency $f^{*}$, as shown in Fig. 9b. Furthermore, the amplitude at the exposed surface decreases with decreasing $g^{*}$, i.e. with increasing resistance.

Since we fit the experimental amplitude as a function of the distance from the exposed surface, we obtain the amplitude at the exposed surface. This amplitude is shown in Fig. 10 for the three different principal transport directions (longitudinal, radial, and tangential) as a function of $\sqrt{ } f^{*}$, using the retrieved diffusion coefficients. For the longitudinal sample, the amplitude at the exposed surface coincidentally corresponds well to $g^{*}=1$. With $\rho=700 \mathrm{~kg} / \mathrm{m}^{3}$, this results in $g=2.04 \cdot 10^{-4} \mathrm{~kg} / \mathrm{m}^{2} \mathrm{~s}$, which is approximately one order of magnitude higher than reported for Western white pine by Avramidis and Siau [8]. Assuming the mass transfer coefficient to be independent of the transport direction, this would result in $g^{*}=52$ and $g^{*}=126$ for the radial and tangential direction respectively. The amplitude at the surface for these cases is shown in Fig. 10 too, which results in a much less steep decay of the surface amplitude than observed in experiments. This would imply a mass transfer coefficient dependent on the exposed surface (radial-tangential, longitudinal-tangential, or radiallongitudinal). As can be seen in Fig. 10, simulations with $g^{*}=4$ 

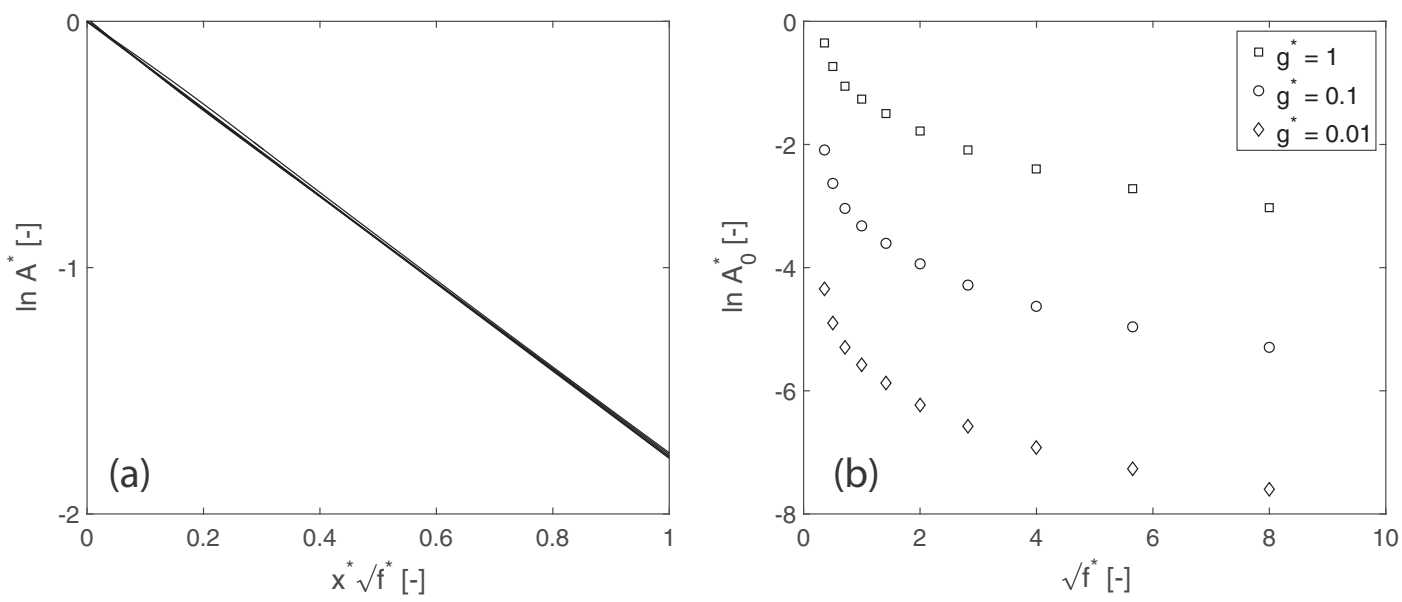

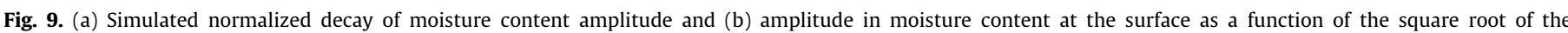
dimensionless frequency $f^{*}$ for different values of the dimensionless surface transfer coefficient $\left(g^{*}=0.01,0.1,1\right)$.

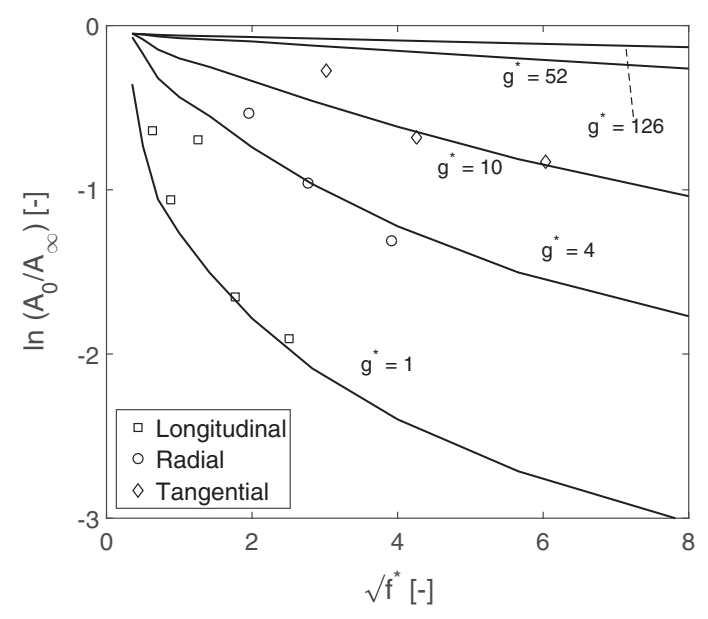

Fig. 10. The amplitude in normalized moisture content at the exposed surface $A_{0}$ as a function of the square root of the dimensionless frequency $f^{*}$ for the three different transport directions in the experiments. Solid lines represent results from numerical simulations.

and $g^{*}=10$ represent the data for the radial and tangential direction fairly well, which, in good agreement with values found by Avramidis and Siau [8], both provide $g=1.5 \cdot 10^{-5} \mathrm{~kg} / \mathrm{m}^{2} \mathrm{~s}$. The longitudinal-tangential and radial-longitudinal surface thus have similar mass transfer coefficients; these surfaces are qualitatively similar. The radial-tangential surface, with its exposed vessels, is different, which could explain the observed difference in mass transfer coefficient.

\section{Conclusions}

During exposure to sinusoidal fluctuations in relative humidity, the amplitude in moisture content in oak decreases exponentially away from the exposed surface. This is in agreement with predictions from the diffusion equation with constant coefficients in a semi-infinite domain. The attenuation of the amplitude is dependent on the direction of transport; due to its low permeability, the amplitude decay is the most severe in the tangential and radial direction. Conversely, the high permeability in the longitudinal direction results in large penetration depths of the humidity fluctuations. The derived diffusion coefficients are in good agreement with literature values. The dependence of the penetration depth in the longitudinal direction on moisture content is shown to be negligible, since experiments in different relative humidity ranges provide similar diffusion coefficients. We also show a dependence of the surface moisture content amplitude on frequency, which can be the result of a resistance to moisture exchange. The values of the mass transfer coefficient are shown to be dependent on the exposed surface, with values for the longitudinal-tangential and radial-longitudinal being approximately one order of magnitude smaller than for the radial-tangential surface.

\section{Conflict of interest}

None.

\section{Acknowledgements}

The authors wish to thank J.H.J. Dalderop and J.J. Noijen for their technical support. This work is part of the research program Science4Arts, financed by the Netherlands Organization for Scientific Research (NWO). The work described in this paper has been carried out in the Darcy Center for porous media research and technology at Eindhoven University of Technology.

\section{References}

[1] O.F. Osanyintola, C.J. Simonson, Moisture buffering capacity of hygroscopic building materials: experimental facilities and energy impact, Energ. Build. 38 (2006) 1270-1282, https://doi.org/10.1016/j.enbuild.2006.03.026.

[2] L. Kuishan, Z. Xu, G. Jun, Experimental investigation of hygrothermal parameters of building materials under isothermal conditions, J. Build. Phys. 32 (2009) 355-370, https://doi.org/10.1177/1744259108102832.

[3] S.P. Casey, M.R. Hall, S.C.E. Tsang, M.A. Khan, Nanocomposite materials for rapid-response interior air humidity buffering in closed environments, J. Build. Perform. Simul. 6 (2013) 354-366, https://doi.org/10.1080/ 19401493.2012.698395.

[4] H. Wan, X. Xu, A. Li, Application analysis of the theoretical moisture penetration depths of conventional building material, Adv. Mech. Eng. 9 (2017) 1-10, https://doi.org/10.1177/1687814017699803.

[5] M. Steeman, A. Janssens, H.J. Steeman, M. Van Belleghem, M. De Paepe, On coupling 1D non-isothermal heat and mass transfer in porous materials with a multizone building energy simulation model, Build. Environ. 45 (2010) 865877, https://doi.org/10.1016/j.buildenv.2009.09.006.

[6] M. Steeman, M. De Paepe, A. Janssens, Impact of whole-building hygrothermal modelling on the assessment of indoor climate in a library building, Build. Environ. $45 \quad$ (2010) 1641-1652, https://doi.org/10.1016/j. buildenv.2010.01.012.

[7] F. Tariku, K. Kumaran, P. Fazio, Integrated analysis of whole building heat, air and moisture transfer, Int. J. Heat Mass Transf. 53 (2010) 3111-3120, https:// doi.org/10.1016/j.ijheatmasstransfer.2010.03.016.

[8] S. Avramidis, J.F. Siau, An investigation of the external and internal resistance to moisture diffusion in wood, Wood Sci. Technol. 21 (1987) 249-256, https:// doi.org/10.1007/BF00351396. 
[9] M.B. MacMillan, M.H. Schneider, A.R. Sharp, B.J. Balcom, Magnetic resonance imaging of water concentration in low moisture content wood, Wood Fiber Sci. 34 (2002) 276-286.

[10] L. Senni, M. Caponero, C. Casieri, F. Felli, F. De Luca, Moisture content and strain relation in wood by Bragg grating sensor and unilateral NMR, Wood Sci. Technol. 44 (2010) 165-175, https://doi.org/10.1007/s00226-009-0268-z.

[11] D.V. Dvinskikh, M. Henriksson, A.L. Mendicino, S. Fortino, T. Toratti, NMR imaging study and multi-Fickian numerical simulation of moisture transfer in Norway spruce samples, Eng. Struct. 33 (2011) 3079-3086, https://doi.org/ 10.1016/j.engstruct.2011.04.011.

[12] Ö. Gezici-Koç, S.J.F. Erich, H.P. Huinink, L.G.J. van der Ven, O.C.G. Adan, Bound and free water distribution in wood during water uptake and drying as measured by 1D magnetic resonance imaging, Cellulose 24 (2017) 535-553, https://doi.org/10.1007/s10570-016-1173-X.

[13] A.V. Luikov, Heat and Mass Transfer in Capillary-Porous Bodies, Pergamon Press, Oxford, 1966

[14] M.J. Cunningham, Effective penetration depth and effective resistance in moisture transfer, Build. Environ. 27 (1992) 379-386, https://doi.org/10.1016/ 0360-1323(92)90037-P.

[15] S. Hameury, M. Sterley, Magnetic resonance imaging of moisture distribution in Pinus sylvestris L. exposed to daily indoor relative humidity fluctuations, Wood Mater. Sci. Eng. 1 (2006) 116-126, https://doi.org/10.1080/ 17480270601150578 .

[16] C. Skaar, Wood-water Relations, Springer-Verlag, Berlin, 1988. 10.1007/978-3642-73683-4.
[17] S. Saft, M. Kaliske, A hybrid interface-element for the simulation of moisture induced cracks in wood, Eng. Fract. Mech. 102 (2013) 32-50, https://doi.org/ 10.1016/j.engfracmech.2013.02.010.

[18] T. Arends, L. Pel, H.P. Huinink, Hygromorphic response dynamics of oak: towards accelerated material characterization, Mater. Struct. 50 (2017) 181, https://doi.org/10.1617/s11527-017-1043-5.

[19] J.F. Siau, Transport Processes in Wood, Springer-Verlag, Berlin, 1984. 10.1007/ 978-3-642-69213-0.

[20] Forest Products Laboratory, Wood Handbook-Wood as an Engineering Material, United States Department of Agriculture, Madison, WI, 2010. 10.2737/FPL-GTR-190.

[21] R.M.E. Valckenborg, L. Pel, K. Hazrati, K. Kopinga, J. Marchand, Pore water distribution in mortar during drying as determined by NMR, Mater. Struct. 34 (2001) 599-604, https://doi.org/10.1007/BF02482126.

[22] E.L. Hahn, Spin echoes, Phys. Rev. 80 (1950) 580-594, https://doi.org/10.1103/ PhysRev. 80.580.

[23] W.T. Simpson, Determination and use of moisture diffusion coefficient to characterize drying of northern red oak (Quercus rubra), Wood Sci. Technol. 27 (1993) 409-420, https://doi.org/10.1007/BF00193863.

[24] R.F. Richards, Steady-flux measurements of moisture diffusivity in unsaturated porous media, Build. Environ. 29 (1994) 531-535, https://doi.org/10.1016/ 0360-1323(94)90012-4.

[25] R. Baronas, F. Ivanauskas, I. Juodeikiene, A. Kajalavicius, Modelling of moisture movement in wood during outdoor storage, Nonlinear Anal.-Model. 6 (2001) $3-14$. 